\title{
Considerations on the management of pyruvate dehydrogenase deficiency
}

\author{
J. Finsterer \\ Krankenanstalt Rudolfstiftung, Messerli Institute, Vienna, Austria
}

[Received: 27 February 2020; Accepted: 10 March 2020]

With interest we read the review article by Ebertowska et al. [3] about the causes, pathogenesis, clinical presentation, diagnosis, and treatment of pyruvate dehydrogenase (PDH) deficiency. The authors concluded that phenylbutyrate could be a beneficial compound in the treatment of PDH-deficiency [3]. We have the following comments.

Elevation of serum and cerebrospinal fluid (CSF) lactate is a common finding in PDH deficiency [10]. Since the degree of lactic acidosis is crucial for the course and outcome of the disease it should not only be determined in the serum but also in the CSF, either by direct measurement in the CSF or by determination with magnetic resonance spectroscopy. Magnetic resonance spectroscopy may show typical lactate peaks [6].

The ketogenic diet may not only be beneficial for refractory epilepsy in patients with mitochondrial disorders [13], but also in patients with migraine [4], autism spectrum disorder [11], obesity [1], and other mitochondrial and non-mitochondrial diseases.

Rarely, PDH deficiency may be complicated by stroke-like episodes (SLEs) [12]. Since SLEs may manifest with seizures, visual impairment, confusion, and muscle weakness and favourably respond to L-arginine, it is crucial to consider SLEs in case of appropriate manifestations not only in mitochondrial encephalopathy, lactic acidosis, and stroke-like episode (MELAS) patients but also in patients with PDH deficiency.

We disagree with the notion that dichloroacetate should be given for lowering lactate levels in PDH patients [3]. In a study of 30 patients with MELAS due to the variant m.3243A $>G$, application of dichloroacetate during a period of 24 months resulted in onset or worsening of peripheral neuropathy in 17 of
19 patients receiving the study drug. In some of the patients neuropathy was irreversible [9].

Concerning the recommendation of phenylbutyrate as a treatment option for PDH deficiency, we want to remind that the compound is not free of side effects. Adverse reactions reported in association with phenylbutyrate treatment include impairment of liver regeneration [8], induction of bipolar disorder [14], or reduction of branched-chain amino acids in acute hepatic injury [7].

Seizures occur in about half of the patients with PHD deficiency [2]. Since some of the antiepileptic drugs (AEDs) are potentially mitochondrion-toxic [5], it is recommended not use mitochondrion-toxic AEDs as first line treatment of epilepsy in PDH-patients. Alternative options for epilepsy treatment not only include the ketogenic diet but also AEDs with low mitochondrion-toxic potential [5].

Overall, this informative and comprehensive review has some limitations and shortcomings, which should be addressed and discussed to further increase the reliability of the conclusions.

\section{REFERENCES}

1. Bruci A, Tuccinardi D, Tozzi R, et al. Very low-calorie ketogenic diet: a safe and effective tool for weight loss in patients with obesity and mild kidney failure. Nutrients. 2020; 12(2), doi: 10.3390/nu12020333, indexed in Pubmed: 32012661.

2. DeBrosse SD, Okajima K, Zhang $S$, et al. Spectrum of neurological and survival outcomes in pyruvate dehydrogenase complex (PDC) deficiency: lack of correlation with genotype. Mol Genet Metab. 2012; 107(3): 394-402, doi: 10.1016/j. ymgme.2012.09.001, indexed in Pubmed: 23021068.

3. Ebertowska A, Ludkiewicz B, Klejbor I, et al. Pyruvate dehydrogenase deficiency: morphological and metabolic effects, creation of animal model to search for curative treatment. Folia Morphol. 2020; 79(2): 191-197, doi: 10.5603/FM.a2020.0020, indexed in Pubmed: 32073132. 
4. Finsterer J, Frank M. low-glycemic-index diet relieving migraine but inducing muscle cramps. J Neurosci Rural Pract. 2019; 10(3): 552-554, doi: 10.1055/s-0039-1698034, indexed in Pubmed: 31595134.

5. Finsterer J, Zarrouk Mahjoub S. Mitochondrial toxicity of antiepileptic drugs and their tolerability in mitochondrial disorders. Expert Opin Drug Metab Toxicol. 2012; 8(1): 71-79, doi: 10.1517/17425255.2012.644535, indexed in Pubmed: 22149023.

6. Giribaldi G, Doria-Lamba L, Biancheri R, et al. Intermittent-relapsing pyruvate dehydrogenase complex deficiency: a case with clinical, biochemical, and neuroradiological reversibility. Dev Med Child Neurol. 2012; 54(5): 472-476, doi: 10.1111/j.1469-8749.2011.04151.x, indexed in Pubmed: 22142326.

7. Holecek M, Vodenicarovova M. Phenylbutyrate exerts adverse effects on liver regeneration and amino acid concentrations in partially hepatectomized rats. Int J Exp Pathol. 2016; 97(3): 278-284, doi: 10.1111/iep.12190, indexed in Pubmed: 27381898.

8. Holeček M. Branched-chain amino acid supplementation in treatment of liver cirrhosis: Updated views on how to attenuate their harmful effects on cataplerosis and ammonia formation. Nutrition. 2017; 41: 80-85, doi: 10.1016/j. nut.2017.04.003, indexed in Pubmed: 28760433.

9. Kaufmann P, Engelstad K, Wei Y, et al. Dichloroacetate causes toxic neuropathy in MELAS: a randomized, con- trolled clinical trial. Neurology. 2006; 66(3): 324-330, doi: 10.1212/01.wnl.0000196641.05913.27, indexed in Pubmed: 16476929.

10. Lissens W, Vreken P, Barth PG, et al. Cerebral palsy and pyruvate dehydrogenase deficiency: identification of two new mutations in the E1alpha gene. Eur J Pediatr. 1999; 158(10): 853-857, doi: $10.1007 /$ s004310051222, indexed in Pubmed: 10486093.

11. Mu C, Corley MJ, Lee RWY, et al. Metabolic framework for the improvement of autism spectrum disorders by a modified ketogenic diet: a pilot study. J Proteome Res. 2020; 19(1): 382-390, doi: 10.1021/acs.jproteome.9b00581, indexed in Pubmed: 31696714.

12. Salih MA, Abdel-Gader AGM, Zahraa JN, et al. Stroke in Saudi children. Epidemiology, clinical features and risk factors. Saudi Med J. 2006; 27 Suppl 1: S12-S20, indexed in Pubmed: 16532126.

13. Spiegler J, Stefanova I, Hellenbroich $Y$, et al. Bowel obstruction in patients with Alpers-Huttenlocher syndrome. Neuropediatrics. 2011; 42(5): 194-196, doi: 10.1055/s0031-1287812, indexed in Pubmed: 22006280.

14. Vitale G, Simonetti G, Pirillo M, et al. Bipolar and related disorders induced by sodium 4-phenylbutyrate in a male adolescent with bile salt export pump deficiency disease. Psychiatry Investig. 2016; 13(5): 580-582, doi: 10.4306/ pi.2016.13.5.580, indexed in Pubmed: 27757140. 